\title{
Comparison of Dynamic Performance of Solar PV fed BLDC Motor Drive with P\&O and I.C. - MPPT Algorithm
}

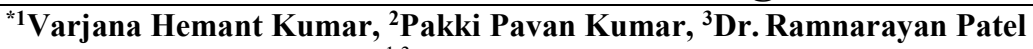 \\ ${ }^{1,3}$ NIT Raipur, C.G., \\ ${ }^{2}$ MVGR College of Engg., A.P. \\ Email: ${ }^{1}$ hemant249v@gmail.com, ${ }^{2}$ pavan.kumar270489@gmail.com, ${ }^{3}$ rnpatel.ee@nitrr.ac.in
}

Received: 06th October 2019, Accepted: 20th November 2019, Published: 31st December 2019

\begin{abstract}
In this paper, the dynamic performance of BLDC motor fed with SPV array using MPPT algorithm such as Perturb \& Observe and Incremental Conductance methods are analysed. The PV array is subjected to varying conditions of temperature and irradiance during its working. The output of SPV array is fed to BLDC motor through DC-DC boost converter to produce maximum output using MPPT algorithms. The dynamic variation of irradiance and temperatures were imposed on to the PV array which produces dynamic variations in the output produced by PV array. This variation in PV output is imposed on to the BLDC motor drive through DC-DC converter, which affects its dynamic performance and hence the life of the motor. This analysis has been done using MATLAB/Simulink 2018b software and waveforms were plotted.
\end{abstract}

\section{Keywords}

Perturb \& Observe (P\&O), Incremental Conductance (IC), Brushless DC (BLDC), DC-DC Converter and Solar Photovoltaic (SPV) Array.

\section{Introduction}

Booming demand of energy continues to put effort for search of new and sustain energy sources. This is full filled by renewable sources of energy, among which Solar has came to be most promise and eminent one. Due to its various advantages such as non-polluting, noise-less operation, low maintenance, free input running cost and longer life makes it a preferable for selection as generating plant [1]. As a stand-alone photovoltaic (PV) systems the main applications are such as domestic and street lighting, water pumping, military and commercial electric vehicles and space applications [1] and the grid-tied configurations are implemented in power plants and hybrid systems [2]. Generally, the SPV generation systems having two main issues: the low conversion efficiency in electrical power generation plants (is due to low irradiances level), and the discontinuous electrical power generation due to changing weather conditions by solar arrays. Despite of severe problems the researchers and industrialists are giving broad attention to SPV system because of drastic reduction in cost of SPV panel and power electronics devices that are used as power conditioners in SPV system [3].

The power conditioners used for extracting maximum efficiency from SPV systems are different DC-DC converters (such as Buck, Boost, Buck-Boost, SEPIC and CUK) which uses different MPPT algorithms for their operation [4, 20]. In the proposed work, the boost converter has been adopted to give MPP for varying solar irradiance and dynamic loadings conditions. The MPPT is a technique engaged to extract maximum power from the SPV system, irrespective of location and dynamic atmospheric conditions. The MPP tracker traces the PV operating voltage corresponding to MPP and locks down the operating point at MPP and extracts maximum power from the SPV array [9, 20]. The SPV systems arrays have non-linear I-V characteristics and output power dependency due to atmospheric conditions. This can be eliminated by tracking the knee point on the P-V curve for maximum power point done with MPPT techniques. The most frequently used MPPT algorithms are Perturb and Observe $(P \& O)$ and the Incremental-Conductance (I.C.). These algorithms are developed on the ideology of Voltage Vs Power characteristic, the deviations in power w.r.t. voltage will be positive $(d P / d V>0)$ on left hand side of the Maximum Power Point (MPP), whereas it is negative $(d P / d V<0)$ on right hand side of the MPP. As they are generic in nature makes them suitable for any PV array, without any basic information about the PV array working conditions, and can be implemented on a simple digital controller. The aim of this paper is to compare the $P \& O$ and $I C$ MPPT algorithms trackers under various dynamic operating conditions of solar array that can help the industry and researchers in choosing the right tracker for a given application. [6]

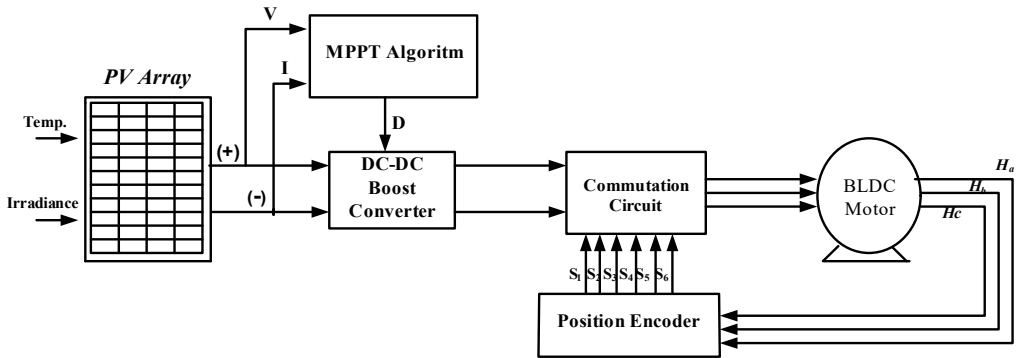

Fig. 1: Block Representation for Proposed System Topology. 


\section{The Proposed System:}

The block representation of proposed system is shown in below Fig.1 consisting of SPV array, DC-DC Boost converter, Commutation circuit and Position Encoder and three phase BLDC motor. A DC-DC Boost converter is connected to the source side of the solar panel in order to intensify the output voltage by varying the duty ratio. The duty ratio fed to the DCDC converter is simulated in accordance to MPPT algorithms used to get the maximum power operating conditions. A commutation circuit is used to excite the phase windings with respect to rotor angular position of BLDC motor. The position encoder encodes the rotor position using halls sensors signal to activate commutation signal for the effective operation of BLDC motor of proposed topology.

Solar Photovoltaic (SPV) System

A SPV system consists mainly of a PV panel comprising of PV cells, whose role is to instantly convert the total incident solar energy into electrical energy.

The equation governing the voltage and current produce by a PV cell [15]

Where,

$$
I_{p v}=I_{p h}-I_{s}\left[\exp \frac{q\left(v_{p v}+R_{s} I_{p v}\right)}{A K T_{a k}}-1\right]-\frac{v_{p v}+R_{s} I_{p v}}{R_{s h}}
$$

$I_{s}:$ is the diode inverse saturation current, $q:$ is the electron charge, $K$ : is the Boltzmann constant, $T_{a k}$ :is the cell temperature of PV (in Kelvin), $A$ : is the non-ideality factor of the junction layer.

\section{DC-DC Boost Chopper Converter}

For obtaining the maximum power from asymmetric solar PV modules, adaptation has to be done in between PV panels and load. This is carried out by DC-DC converters which are regulated by MPPT algorithms.

A Boost DC-DC converter topology has been chosen to step-up DC voltage levels as required by 3- $\phi$ inverter to run the motor load which is shown in Fig.2.

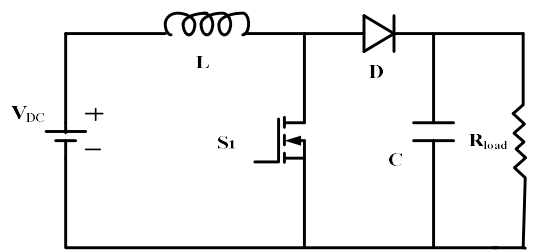

Fig. 2: The DC-DC Boost Converter Circuit.

In the circuit, the MOSFET $\mathrm{S}_{1}$ is turned ON through the firing pulse developed by MPPT algorithm, so the current flow takes place via the inductor (L) which makes it store energy. The stored energy in the inductor will develop a voltage across it, which gets added to the input voltage, when S1 is turned OFF. Now, the voltage input and voltage developed across the inductor are in series and together charge the capacitor $(\mathrm{C})$ to a voltage greater than input voltage [16]. The above circuit can be design using the differential equations shown below [17].

The duty ratio, D of the switch S1 shown in circuit can be calculated using below equation (1) with input and desired output voltages, $V_{o}$ and $V_{i}$ respectively:

$D=1-\frac{V_{i}}{V_{o}}$

The inductor value is chosen considering the allowable current ripple for the maximum voltage is given below:

$L=\frac{V_{o}\left(V_{i}-V_{o}\right)}{\Delta I_{L} \cdot f_{S} \cdot V_{o}}$

Where $\Delta I_{L}$ is permissible ripples in inductor current and for current continuous mode the value of inductor is calculated as: $L_{c}=\frac{D \cdot(1-D)^{2} \cdot R_{O}}{2 \cdot f_{S}}$

The value of capacitor is designed considering the ripples in output voltage, which is given in equation (4):

$C=\frac{D}{R_{o} f_{s}\left(\frac{\Delta V_{o}}{V_{o}}\right)}$

Where $\Delta V_{o}$ is preferred ripple in voltage output with supply frequency of operation $\left(f_{s}\right)$ and at output load $\left(R_{o}\right)$.

\section{Commutation Circuit \& Position Encoder}

A DC-AC inverter circuit is used to convert DC power form SPV into AC power of required frequency and voltage with IGBT switched configuration. A steady output voltage with reduced harmonic distortions can achieve by controlling power provided by the DC source by an inverter [10]. The Position Encoder is used to develop the commutation sequence in order to control method the semiconductor switches and to synchronize phase between inverter DC input voltage from PV panel and BLDC motor [11]. 


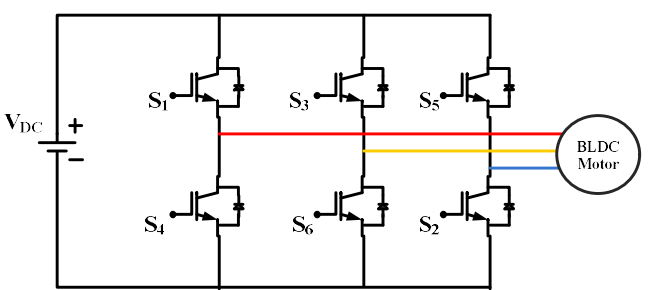

Fig. 3: 3- $\phi$ DC-AC Converter Circuit.

\section{MPPT Algorithm:}

The variations in irradiance level, panel temperature and V-I characteristic of solar PV array, led to variation in MPP, (as it is the function of, level of irradiance, ambient temperature, efficiency of the heat exchange process and operating point of the panels). It is essential to track regularly the MPP to enhance the output power from a solar PV system, for the considered operating conditions [12]. The MPPT can be achieved by different approaches like fuzzy logic, neural networks, pilot cells and DSP based implementations which have been proposed in [13-15].

A regular solar PV panel has 30 - $40 \%$ conversion efficiency, of the available solar radiation to electrical energy. Hence MPPT techniques are utilised to enhance the efficiency of PV panel. According to maximum power transfer theorem, the output power of a given circuit will be maximum, when the source impedance of the circuit becomes equal to load impedance, so by this concept the maximum power point converges to a problem of impedance matching. Hence Perturb \& Observe (P\&O) and Incremental conductance (IC) MPPT algorithms are mostly used along with solar PV system to enhance power generation under every atmospheric condition because of its ease of implementation.

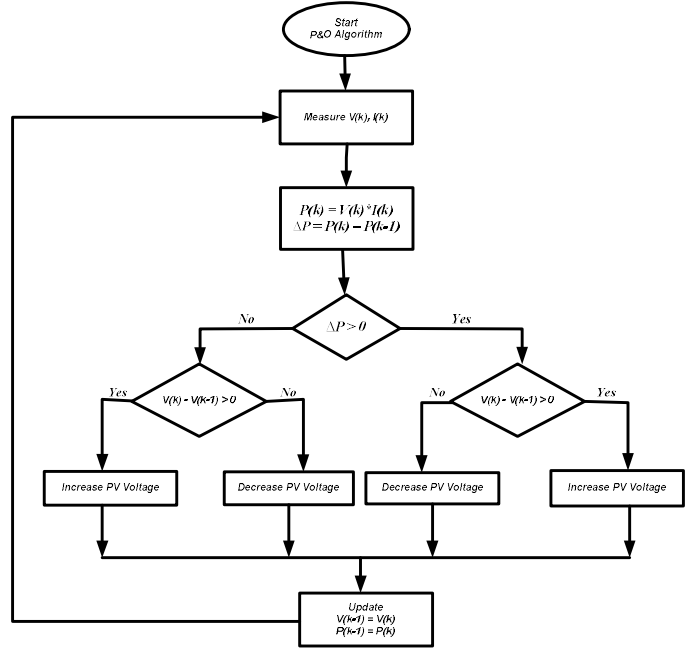

Fig. 4: Flowchart of P\&O MPPT Algorithm.

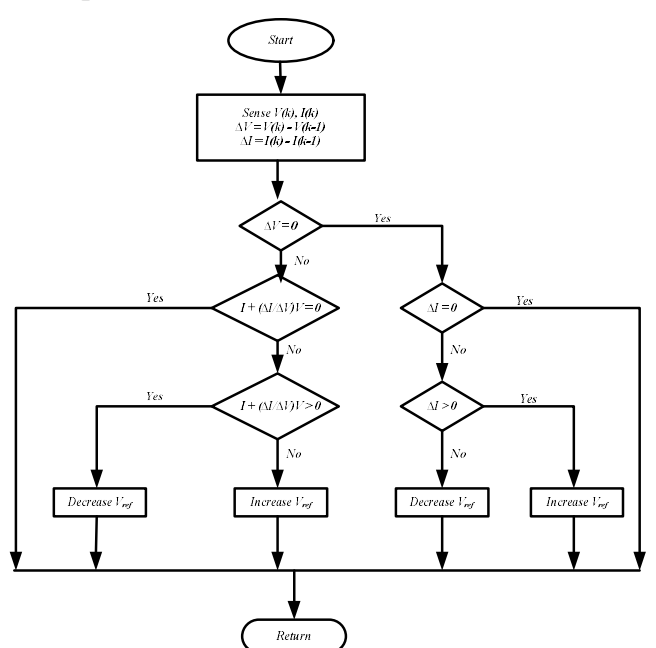

Fig. 5: Flowchart of IC MPPT Algorithm

\section{Perturb and Observe Algorithm}

In P\&O method, the algorithm for MPPT is focused on the calculation of output power and changes in output power by sampling both, the PV array voltage and current. The tracker observes variations in voltage $(\Delta \mathrm{V})$ and the voltage of the PV panel is incremented or decremented periodically. If the perturbation gives rise to an increase/decrease in differential change in power $(\Delta \mathrm{P})$ of $\mathrm{PV}$ array, then the consequent perturbation is developed in the same/opposite direction [16]. The variation of duty cycle fed to DC chopper is continuously changed until the maximum power point is achieved. This variation produces oscillation in system which can be diminished by decreasing the step size of perturbation. For various values of solar irradiance and temperatures, the PV array show diverse PV characteristic curves having different maximum power point. The voltage value at point where maximum power corresponds maximum voltage in the curve is supplied to the DCDC converter for its operation. The above figure depicts the P\&O algorithm for MPPT.

\section{Incremental Conductance Algorithm}

In Incremental Conductance algorithm, both voltage and current values are considered for comparison among change in conductance $(\mathrm{dI} / \mathrm{dV})$ and instantaneous conductance $(\mathrm{I} / \mathrm{V})$ [17]. As soon as, the maximum power point is achieved the following basic conditions are satisfied:

$\frac{d P}{d V}=0$
$\frac{d P}{d V}>0$
$\frac{d P}{d V}<0$
$\frac{d P}{d V}=\frac{d(V I)}{d V}=I+\frac{V \cdot d I}{d V}$ 
The $d P / d V$ is the identification factor of maximum power point which tells us the sensitivity of tracker to fluctuate either right or left of MPP curve [18].

$\frac{d I}{d V}=-\frac{I}{V}$

Until $(d I / d V)+(I / V)=0$ condition is satisfied, the MPPT adjusts the switching signal of DC-DC converter for proper conversion. Here, the error caused by variations in irradiance is also removed [19]. The flowchart of incrementalconductance MPPT algorithm is shown above in Fig.5. Both algorithms were used to stimulate the proposed topology model and waveforms were plotted.

Simulations and Results:

The overall proposed simulink topology as shown in block diagram of Fig.1 has been simulated and MPPT algorithms are coded with help of function block in MATLAB 2018a version.
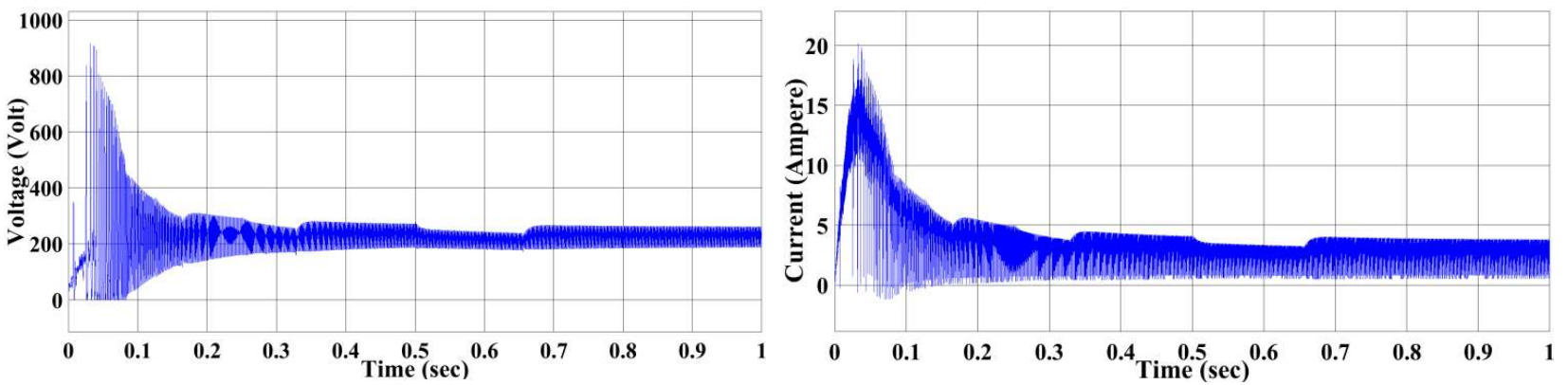

Fig. 6(a): Output Voltage of DC-DC Converter with I.C.

Fig. 6(b): Output Current of DC-DC Converter with I.C.

In the simulation runtime of Simulink, at exactly half of the runtime, a change in irradiance and temperature has been simulated to observe the dynamic performance of BLDC motor drive and the DC-DC Boost convertor which is controlled using I.C. and P\&O MPPT algorithms. The below figures show the output voltage, current and torque for irradiance varying from $600 \mathrm{~W} / \mathrm{m}^{2}$ to $1200 \mathrm{~W} / \mathrm{m}^{2}$ and temperature varying from $25^{\circ} \mathrm{C}$ to $40^{\circ} \mathrm{C}$ for a SPV system working with a boost converter using $\mathrm{P} \& \mathrm{O}$ and IC Algorithm. The system has been designed for a duty ratio of 0.66 . Hence the input voltage of $75 \mathrm{~V}$ has been increased to $220 \mathrm{~V}$ under standard conditions i.e. $1000 \mathrm{w} / \mathrm{m}^{2}$ irradiance and $30^{\circ} \mathrm{C}$ temperature.

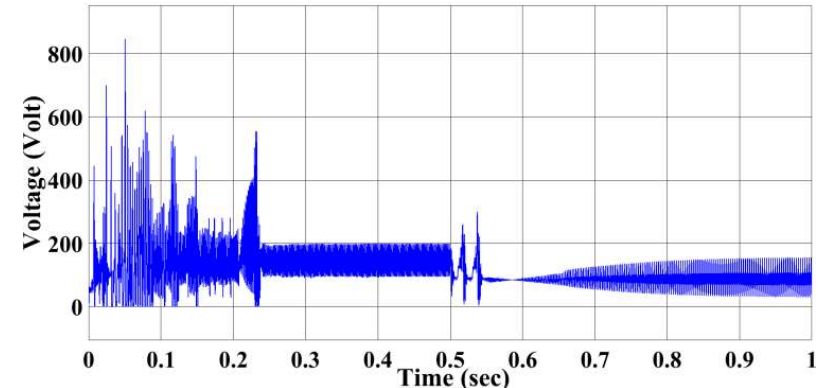

Fig. 7(a): Voltage Output of DC-DC Converter with P\&O

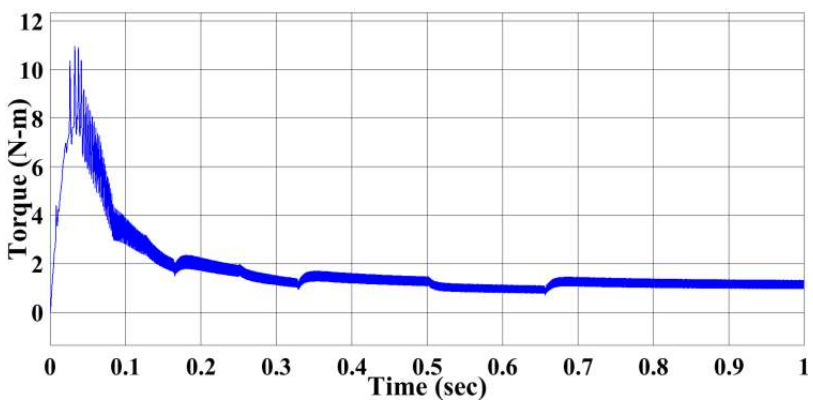

Fig. 8 (a): Torque Developed by BLDC Motor with I.C.

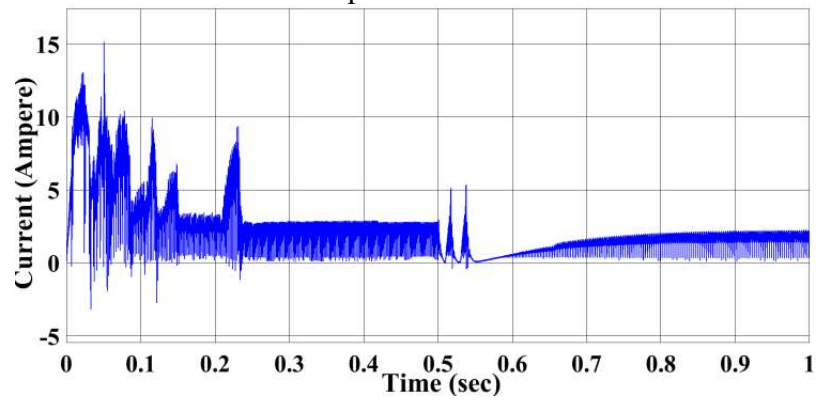

Fig. 7(b): Current Output of DC-DC Converter with

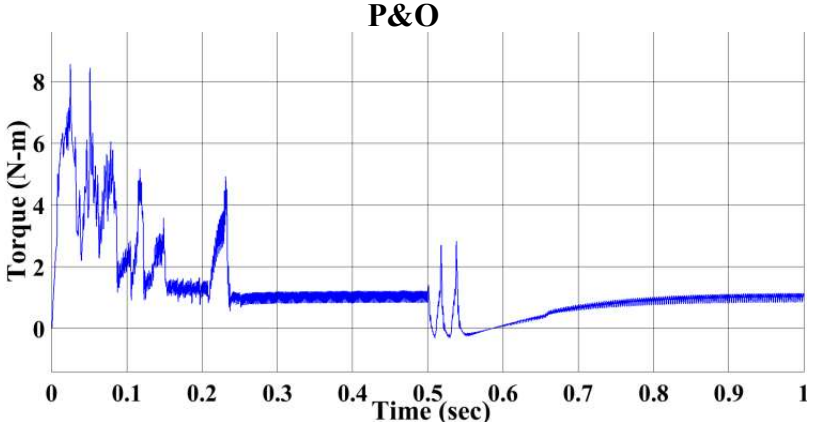

It can be observed from the results that, the output voltage and current from boost converter, in case of I.C. method is as per the requirements of the BLDC motor and has fewer variations than that of P\&O method. The torque output of the BLDC motor is more pulsating in nature for P\&O method than that of I.C., which produced smooth torque. The dynamic change in 
temperature and irradiance has much effected in the case of $\mathrm{P} \& \mathrm{O}$ method than that in the case of I.C which is depicted in the below comparison table.

\begin{tabular}{|c|c|c|c|c|c|}
\hline \multirow{2}{*}{ Marameters } & \multicolumn{2}{c|}{ Incremental Conductance (I.C.) } & \multicolumn{2}{c|}{ Perturb \& Observe (P\&O) } \\
\cline { 3 - 6 } & $\boldsymbol{T}<\boldsymbol{0 . 5 s}$ & $\boldsymbol{T}>\boldsymbol{0 . 5 s}$ & $\boldsymbol{T}<\boldsymbol{0 . 5 s}$ & $\boldsymbol{T}>\boldsymbol{0 . 5 s}$ \\
\hline Voltage & Steady state value & $241.6 \mathrm{~V}$ & $231.3 \mathrm{~V}$ & $145.1 \mathrm{~V}$ & $90.19 \mathrm{~V}$ \\
\hline Current & Steady state value & $2.70 \mathrm{~A}$ & $2.66 \mathrm{~A}$ & $2.33 \mathrm{~A}$ & $1.83 \mathrm{~A}$ \\
\hline Torque & Steady state value & $1.3 \mathrm{~N}-\mathrm{m}$ & $1.15 \mathrm{~N}-\mathrm{m}$ & $1.09 \mathrm{~N}-\mathrm{m}$ & $1.01 \mathrm{~N}-\mathrm{m}$ \\
\hline \multicolumn{2}{|c|}{ No. of transients } & 1 & 0 & 6 & 2 \\
\hline
\end{tabular}

Table 1: Comparison of DC-DC Boost Converter Output

\begin{tabular}{|c|c|c|c|c|c|}
\hline \multicolumn{6}{|c|}{ Specifications } \\
\hline Sl.no. & Solar PV Array & Value & Sl.no. & BLDC Motor & Value \\
\hline 1 & Cells per module & 58 & 1 & $\begin{array}{c}\text { Stator Resistance/phase, } \mathrm{R}_{\mathrm{s}} \\
(\Omega)\end{array}$ & 5.17 \\
\hline 2 & Parallel strings & 10 & 2 & $\begin{array}{l}\text { Stator phase inductance, } \mathrm{L}_{\mathrm{s}} \\
(\mathrm{mH})\end{array}$ & 24 \\
\hline 3 & Series connected modules per string & 2 & 3 & Torque constant, $\mathrm{K}_{\mathrm{t}}(\mathrm{N}-\mathrm{m} / \mathrm{A})$ & 0.641 \\
\hline 4 & Open circuit Voltage, $\mathrm{V}_{\mathrm{oc}}(\mathrm{V})$ & 37 & 4 & $\begin{array}{l}\text { Voltage constant, } \mathrm{K}_{\mathrm{b}} \\
(\mathrm{V} / \mathrm{krpm})\end{array}$ & 67.125 \\
\hline 5 & $\begin{array}{l}\text { Voltage at maximum power point, } \\
\qquad V_{m p}(V)\end{array}$ & 31.09 & 5 & Inertia, $\mathrm{J}\left(\mathrm{kg}-\mathrm{m}^{2}\right)$ & 0.0027 \\
\hline 6 & Short circuit current, $\mathrm{I}_{\mathrm{sc}}(\mathrm{A})$ & 8.55 & 6 & Viscous coefficient, F (N-m.s) & 0.0004924 \\
\hline 7 & $\begin{array}{l}\text { Current at maximum power point, } \mathrm{I}_{\mathrm{mp}} \\
\text { (A) }\end{array}$ & 8.09 & 7 & Pole pairs & 4 \\
\hline
\end{tabular}

Table 2: Solar PV Array and BLDC Motor Data

\section{Conclusion}

It can be concluded from the above results that the I.C. based MPPT algorithm has produced better dynamic performance in the case of solar PV fed BLDC motor drive than that of P\&O algorithm. The BLDC motor drive performance can be much enhanced by implementing a proper commutation and torque control methodology. The same analysis can also be done in the case of other DC-DC converters available.

\section{References}

1. Pallavee Bhatnagar, and R.K.Nema," Maximum power point tracking control techniques: State-of-the-art in photovoltaic applications", ELSEVIER Transaction in Renewable and Sustainable Energy Reviews 23 (2013) 224-241.

2. A. Dolara, R. Faranda and S. Leva," Energy Comparison of Seven MPPT Techniques for PV Systems", Scientic Research Transaction in J. Electromagnetic Analysis \& Applications, 2009, 3: 152-162.

3. Rajan Kumar and Bhim Singh, "Buck-Boost Converter Fed BLDC Motor Drive for Solar PV Array Based Water Pumping", IEEE International Conference on Power Electronics, Drives and Energy Systems (PEDES), 2014.

4. F.A.O. Aashoor and F.V.P. Robinson, "Maximum Power Point Tracking of Photovoltaic Water Pumping System Using Fuzzy Logic Controller,” 48th International Universities' Power Engineering Conference (UPEC), pp.1-5, 2-5 Sept. 2013.

5. Tafticht T, Agbossou K. Development of a MPPT method for photovoltaic systems. In: Canadian Conference on Electrical and Computer Engineering; 2004. p. 1123-6.

6. Dezso Sera;et.al, "On the Perturb-and-Observe and Incremental Conductance MPPT Methods for PV Systems", IEEE Journal Of Photovoltaics, VOL. 3, NO. 3, JULY 2013.

7. Saidi Khadidja; et.al, "Comparative study of Incremental Conductance and Perturb \& Observe MPPT Methods for Photovoltaic System”, 978-1-5090-6287-4/17/\$31.00 C2017 IEEE.

8. Hart, Daniel W. Power electronics. Tata McGraw-Hill Education, 2011.

9. Pooja Sahu, Deepak Verma and Dr. S Nema, "Physical Design and Modelling of Boost Converter for Maximum Power Point Tracking in Solar PV", 2016 International Conference on Electrical Power and Energy Systems (ICEPES).

10. Mohammad Halimur Rahman: et.Al, "Design and Implementation of a Three-Phase Inverter Operated with Different Conduction Modes", 2019 International Conference on Robotics, Electrical Signal Processing Techniques (ICREST).

11. Tawfikur Rahman, S. M. A. Motakabber and M. I. Ibrahimy, "Design of a Switching Mode Three Phase Inverter", 2016 International Conference on Computer \& Communication Engineering.

12. Nicola Femia: et. Al, "Optimization of Perturb and Observe Maximum Power Point Tracking Method", IEEE Transactions On Power Electronics, VOL. 20, NO. 4, JULY 2005.

13. K. Irisawa, T. Saito, I. Takano, and Y. Sawada, "Maximum power point tracking control of photovoltaic generation system under non-uniform insolation by means of monitoring cells," in Proc. 28th IEEE Photovoltaic Specialists Conf., Sep. 2000, pp. 1707-1710. 
14. C. Hua, J. Lin, and C. Shen, "Implementation of a DSP-controlled photovoltaic system with peak power tracking," IEEE Trans. Ind. Electron.,vol. 45, no. 1, pp. 99-107, Feb. 1998.

15. T. Wu, C. Chang, and Y. Chen, "A fuzzy-logic-controlled single-stage converter for PV-powered lighting system applications,” IEEE Trans.Ind. Electron. vol. 47, no. 2, pp. 287-296, Apr. 2000.

16. Jacob James Nedumgatt, Kothari D P; et.al, "Perturb and Observe MPPT Algorithm for Solar PV Systems-Modeling and Simulation", Published in Annual IEEE India Conference 2011,DOI:10.1109/indcon.2011.6139513.

17. S. Uma Ramani, Sathish Kumar Kollimalla and B. Arundhati, "Comparative Study of P\&O and Incremental Conductance method for PV System”, 2017 International Conference on circuits Power Computing Technologies [ICCPCT].

18. Loredana Cristaldi; et. al., "An Improved Model-Based Maximum Power Point Tracker for Photovoltaic Panels", IEEE Transactions On Instrumentation And Measurement, VOL. 63, NO. 1, January 2014.

19. Azadeh Safari and Saad Mekhilef, "Simulation and Hardware Implementation of Incremental Conductance MPPT with Direct Control Method Using Cuk Converter", IEEE Transactions on Industrial Electronics, Vol. 58, No. 4, April 2011.

20. U. Srikanth, P. Pavan Kumar, K.V.V.Prasad "A Comprehensive Comparison Of MPPT Algorithms With DC-DC Converters For Solar PV Array”, Journal of Emerging Technologies and Innovative Research (JETIR), JETIR (ISSN-23495162), Volume 4, Issue 09, pp 41-52, September 2017. 